\title{
Application of Micro Gas Turbine in Range-Extended Electric Vehicles
}

\author{
Apostolos Karvountzis-Kontakiotis ${ }^{\mathrm{a}, \mathrm{b}}$, Amin Mahmoudzadeh Andwari ${ }^{\mathrm{a}, \mathrm{d}^{*}}$ Apostolos Pesiridis ${ }^{\mathrm{a}}$, \\ Salvatore Russo ${ }^{c}$, Raffaele Tuccillo ${ }^{c}$ and Vahid Esfahanian ${ }^{\mathrm{d}}$ \\ ${ }^{a}$ Centre for Advanced Powertrain and Fuels Research (CAPF), Department of Mechanical, \\ Aerospace and Civil Engineering, Brunel University London, London UB8 3PH, UK \\ ${ }^{\mathrm{b}}$ Department of Mechanical Engineering \& Aeronautics, City University of London, \\ Northampton Square, London EC1V 0HB, UK \\ ${ }^{c}$ Department of Industrial Engineering, University of Naples Federico II, Via Claudio 21, \\ Napoli, Italy \\ ${ }^{\mathrm{d}}$ Vehicle, Fuel and Environment Research Institute, School of Mechanical Engineering, College \\ of Engineering, University of Tehran, Tehran 1439956191, Iran \\ *Corresponding author E-mail: amin.mahmoudzadeh@ut.ac.ir
}

\begin{abstract}
The increasing number of passenger cars worldwide and the consequent increasing rate of global oil consumption have raised the attention on fuel prices and have caused serious problems to the environment. Nowadays, the demand for reducing fuel consumption and pollutant emissions has paved the way to the development of more efficient power generation systems for the transportation sector. The lower fuel burning and pollutant emissions of hybrid electric vehicles give a strong motivation and encourage further investigations in this field. This research aims to investigate novel configurations, which could achieve further performance benefits for vehicle powertrain. Automakers claim that the employment of a gas turbine operating as range extender in a series hybrid configuration is the most efficiency solution in the coming years. In particular, a Micro Gas Turbine (MGT) can be considered as an alternative to the internal combustion engine (ICE) as a range extender for electric vehicles. The MGT produces less raw exhaust gaseous emissions such as $\mathrm{HC}$ and $\mathrm{CO}$ and static applications compared to the ICE. In addition, the MGT weight is lower than an equivalent ICE and potentially can reduce the level of $\mathrm{CO}_{2}$ especially in a vehicle application. This study presents a parametric study of MGT applications for Range-Extended Electric Vehicle (REEV). The main objective is to examine the MGT performance to meet the requirements for a REEV that could become competitive, in terms of fuel consumption and pollutant emissions, to equivalent diesel or gasoline hybrid propulsion units or to conventional diesel vehicle.
\end{abstract}


Keywords: Micro Gas Turbine; Range-Extended Electric Vehicle; Auxiliary Power Unit; Specific Fuel Consumption; Exhaust Emissions

\section{Introduction}

The reduction of fuel consumption of passenger cars is a challenging goal. Many approaches that promise to reduce the fuel consumption and the emissions of passenger cars have been presented so far, and new ideas emerge on a regular basis [1,2]. One technology currently available is the electric vehicle, but their mass production is inhibited by a source of barriers. Range-Extended Electric Vehicle (REEV) is a solution to the limited range and exorbitant cost of Battery Electric Vehicles (BEVs). They operate essentially as a BEV until their batteries become depleted; at this point they utilize an Auxiliary Power Unit (APU) that draws energy from liquid or gaseous fuel and provides electricity, allowing the vehicle to continue operating [3-8]. The APU generally only provides the average power demanded by the vehicle, so it can be downsized compared to the power unit of a conventional vehicle. In addition, because the APU is decoupled from the road load, its operation can be optimized to produce high efficiency and low exhaust emissions [9-14]. Furthermore the main requirements of APU are compactness, lightweight to minimize the vehicle efficiency penalty of carrying dead weight, low noise and vibration, inexpensive and little maintenance. So the Micro Gas Turbines have the potential source to be an alternative APU in the REEVs [15-21].

This work presents an assessment of a novel hybrid configuration comprising a MGT, a battery pack, and a traction electric motor, focusing on its potential contribution to the reduction in fuel burn and pollutant emissions. The main purpose of this study is to evaluate the MGT performance through appropriate software to meet the requirements for a REEV that becomes competitive in terms of performance to equivalent diesel or gasoline hybrid propulsion units or to conventional diesel vehicle. The power required for the propulsion of the vehicle is provided by the electric motor. The electric power is stored by the batteries, which are charged by a periodic function of the MGT. The MGT starts up when the battery state of charge becomes lower than $20 \%$, and its function continues until the battery reaches a state of charge of $80 \%$. The performance of the vehicle is investigated using a specific REEV model built in MATLAB ${ }^{\circledR}$ software. The simulations are carried out using a quasi-static approach. The calculated 
performances, in terms of fuel consumption and pollutant emissions, are compared with those of an equivalent hybrid vehicle having a diesel engine (at the same power of the MGT) as APU, and with the performances of a conventional diesel vehicle. The simulations are carried out also for different fuels supplying the MGT and at different ambient temperatures, to show the MGT's operation limits at high ambient temperatures. The sensitivity of the results to the variation in the vehicle parameters such as mass, and battery type is calculated to identify the conditions under which the application of this hybrid technology offers potential benefits.

\section{Modeling Approach}

\subsection{Vehicle and Powertrain Modeling}

A generic in-house vehicle model was developed in this study, based on MATLAB ${ }^{\circledR}$, to predict the performance characteristics of various powertrain types of passenger vehicles. The theoretical background of this model has been presented in previous studies $[1,12,14]$. Briefly, the simulated vehicle is discretized on a number of sub-models (components) including vehicle (body), electric motor/generator, battery, gearbox and thermal engine. Proper selection of the components can result in the simulation of a conventional vehicle or a REEV. Inputs of the model are the geometrical characteristics of the components as well as the driving conditions, such as velocity and road slope angle versus time. At each time step, calculations of the vehicle energy flow are performed on both ways, forward and backwards. Initially, calculations are performed at a forward flow from wheel to tank, to calculate the required energy, while backward calculations are performed to ensure that each component would never require higher torque or power than that being able to be delivered by the respective component placed upstream. The comparison between the conventional diesel vehicle and the MGT REEV is performed by utilizing New European Driving Cycle (NEDC).

\subsubsection{Powertrain Modeling}

The first step to model vehicle performance is to calculate the tractive forces of the vehicle for a given velocity and slope of angle driving profile. The forces which are applied on the vehicle are rooted on rolling resistance, aerodynamic drag, road inclination and vehicle's acceleration, when velocity is changed. The sum of rolling resistance force (Eq. 1), aerodynamic 
drag force (Eq. 2), gradeability driving force (Eq. 3), the acceleration force (Eq. 4) and the angular acceleration force results the tractive effort at each time step (Eq. 5) [22-25].

$F_{r r}=\mu_{r r} \cdot m \cdot g$

$F_{a d}=(1 / 2) \cdot \rho \cdot A \cdot C_{d} \cdot v^{2}$

$F_{h c}=m \cdot g \cdot \sin (\psi)$

$F_{l a}=m \cdot a$

$F_{t e}=F_{r r}+F_{a d}+F_{h c}+F_{l a}+F_{\omega a}$

The angular acceleration force $F_{\omega a}$ is considered in this study as a $5 \%$ increase of the acceleration force $F_{l a}$ value. Fig. 1 schematically presents the forces acting on vehicle's motion.

Fig. 1: Schematic representation for uphill driving [26]

The tractive effort power as well as the required power and angular speed $(\omega)$ of the motor or engine are described in equations Eq. 6, Eq. 7 and Eq. 8 respectively. Finally, the mean brake effective torque is calculated by Eq. 9:

$P_{t e}=F_{t e} \cdot v(t)$

$\omega=G \cdot \frac{v(t)}{r}$

$P_{\text {mot_out }}=\frac{P_{\text {te }}}{\eta_{G}}$

$T=\frac{P_{\text {mot_out }}}{\omega}$

The electric motor that has been assumed in this study is a DC electric motor with $200 \mathrm{Nm}$ maximum torque between 200 and $2500 \mathrm{rpm}$ while its maximum power is $60 \mathrm{~kW}$ at 4000rpm. The efficiency of the DC electric motor in this study has been simply simulated by using Eq. 10, as a function of torque and rotational speed [26, 27]. The efficiency of its controller is also assumed in this formula. The coefficients for copper, iron, windage and other constant losses are described in Table 1.

$\eta_{m}=\frac{T \cdot \omega}{T \cdot \omega+k_{c} \cdot T^{2}+k_{i} \cdot \omega+k_{w} \cdot \omega^{3}+C}$ 
Table 1: Coefficients used for electrical power of motor

During acceleration or breaking the electric machine operates either as an electric motor or a generator (in the case of regenerative breaking) respectively. At each case, the required power is described by Eq. 11 and Eq. 12 respectively.

$$
\begin{aligned}
& P_{\text {mot_in }}=\frac{P_{\text {mot_out }}}{\eta_{m}} \\
& P_{\text {mot_in }}=P_{\text {mot_out }} \cdot \eta_{m}
\end{aligned}
$$

The battery pack unit has been modeled by utilizing the well-established "equivalent circuit model" $[18,28]$, while in this work the work a Nickel-Cadmium battery has been chosen. The state of charge of a NiCad battery is described by some former researches [31, 32]. The instantaneous current through the battery pack is calculated from the battery power [27]. The latter is a sum of power consumption and generation by the motor, the vehicle auxiliaries and the thermal engine as explained by Eq. 13. In this work, the vehicle auxiliaries were selected to be equal 250 Watt.

$P_{\text {bat }}=P_{\text {mot_in }}+P_{a c}-P_{\text {engine }}$

\subsubsection{Range Extender Electric Vehicle}

The mathematical vehicle model presented in the previous section has been employed to simulate an indicative REEV. The model consists of a thermal engine, a battery pack, an electric motor and a transmission gearbox, while the energy flow is schematically presented in Fig. 2. The studied REEV was configured to be representative to already existing commercial range extender vehicles and its respective model parameters as summarized in Table 2. The vehicle has a single gear and its weight is higher to conventional vehicles, mainly due to the battery pack and the complex powertrain system.

Table 2: Main REEV parameters 
Fig. 2: Energy flows in the vehicle

Depending on the pedal positions, the controller receives input signals, processes, and transmits them directly to the power converter, which controls the power provided by the battery to the electric motor or, conversely, the power from the electric motor to the battery when the vehicle decelerates. The energy management unit is connected to the controller, the battery, and the MGT, and its main aim is to achieve the communication and control of these three components in terms of energy input and output to the battery. Finally, the auxiliary system consumes an amount of energy from the battery to cover the needs of the driver (radio, headlights, air conditioning, heating, etc.) [29-33]. Fig. 3 schematically presents complete simulation process of the REEV that has been conducted in this study.

Fig. 3: Flowchart for the simulation of Range-Extended Electric Vehicle (REEV)

\subsubsection{Conventional Vehicle}

The mathematical vehicle model presented in the previous section has been employed to simulate a conventional passenger diesel car to compare it with the REEV. This simple powertrain model consists of a thermal engine, the transmission gearbox, the differential and the wheels. The vehicle and gearbox main characteristics are described in Table 3 and Table 4 respectively.

Table 3: Diesel car main parameters.

Table 4: Diesel car transmission characteristics

The conventional vehicle model transforms the driving cycle velocity profile into torque-speed profile and utilizes engine maps to calculate the instantaneous fuel consumption and emissions values. At the end of the simulation process, the cumulative fuel consumption and NOx emissions values are calculated and compared with the performance of the REEV. 


\subsection{Micro Gas Turbine Modelling}

Initially, it is required to build a model of Capstone C30 micro gas turbine, to simulate its performances both in design point and in all its others operating points. The purpose is to build the complete maps of MicroTurbine in order to predict its performances in all operating conditions. Capstone C30 can be operated both with gaseous fuels and with liquid fuels, and its performances change depending on the kind of fuel used. Firstly it is assumed to supply the MicroTurbine by a gaseous fuel, in particular natural gas, which has the Low Heating Value $(\mathrm{LHV})=46280 \mathrm{~kJ} / \mathrm{kg}$. After, the same procedure is performed by a liquid fuel, and for this case only the main results will be presented. Table 5 represents performance of Capstone Model C30 MicroTurbine operated by natural gas fuel at full load power and ISO conditions (as Capstone Turbine Corporation declares), which defines the cycle design point of the MGT chosen [30, 3440].

Table 5: MGT cycle design point claimed from Capstone Turbine Corporation

Starting from these data, using the commercial software called GASTURB11 (GasTurb11), the model of this MGT at the design point is built. So, after calibration of the model, it is validated comparing the values of design cycle point obtained from the software with the values declared by Capstone Company at nominal point of Model C30 as represented in Table 6.

Table 6: Performance parameters comparison between simulated MGT and base Capstone MGT

The next step is to define the performances of the MGT in all its operating conditions. In other terms, the complete operating maps of main parameters of MicroTurbine are built through an Off-Design analysis of MicroTurbine using GASTURB11 software. Accordingly, the compressor and turbine maps of the Capstone C30 are built by computerizing data existing in literature, using the tools Smooth C and Smooth T. Once the design and the calculation of the maps are implemented, it is possible to make the Off-Design analysis of MicroTurbine. The Off-Design is followed by choosing only two parameters of MicroTurbine and making these two parameters modified in a specific range of values, in accordance with the right operation of machine. Having fixed all other parameters (in particular the ambient temperature), the performances of Capstone 
C30 can be calculated varying the Turbine Inlet Temperature (T.I.T.) and the Relative Rotational Speed (ratio between rotational speed and rotational speed at design point) into specific ranges and with specific Step sizes, as shown in Table 7.

Table 7: Off-Design parameters analysis of MicroTurbine

The maximum of T.I.T. has been imposed in accordance with the materials resistance used for the turbine, and this value of $1200 \mathrm{~K}$ is a good value for the common materials used. The results of this Off-Design analysis are the performances of the MicroTurbine in all operating points defined by the variation of the two parameters T.I.T. and relative rotational speed. Thanks to this analysis, the complete operating maps of main operating parameters of C30 are plotted as presented in Fig. 4 and Fig. 5.

Fig. 4: MGT C30 Thermal Efficiency Map

Fig. 5: MGT C30 Brake Specific Fuel Consumption (BSFC) Map

The calculation of the NOx emissions is not performed by GASTURB11, but by a more precious and specific calculation code (MGTOFFDES Code). This code is created specifically for simulating the combustion process of Capstone $\mathrm{C} 30$, so it takes account of the real main aspects of the combustor of this MicroTurbine (geometry, air flow distribution) and the way in which the combustion process evolves in time (the injection strategies). Fig. 6 and Fig. 7 illustrate the real C30 combustion chamber for gaseous fuel, and the fuel injectors. The calculation code used for the NOx emissions takes account of these real characteristics of the MGT.

Fig. 6: MGT C30 combustion chamber for gaseous fuel

Fig. 7: MGT C30 Fuel Injectors

The Model C30 MicroTurbine utilizes three pilot injector solenoids, and a single premix solenoid to control fuel flow to the engine. Injector operation changes at different power levels:

- Below $7 \mathrm{~kW}$, the MicroTurbine operates with a single pilot injector. 
- From $7 \mathrm{~kW}$ to $22 \mathrm{~kW}$, all three pilot injectors are switched on.

- Above $22 \mathrm{~kW}$, all three pilot solenoids are turned off, and the premix solenoid is switched on.

So, starting from these real data, the calculation code enables us to calculate the NOx emissions, both at design point and in all other operating points of the MGT, through an Off-Design analysis, followed the theoretical approach as explained in Table 8.

Table 8: Theoretical approach developed through Off-Design procedure

The code is based on a Thermo-Kinetic model, linked to the extended Zel'dovich mechanism, for the prediction of the thermal NO formation, whose development is briefly outlined bellows by Eq. 14, Eq. 15, Eq. 16 and Eq. 17 [1, 13, 23]:

$$
\begin{gathered}
O+N_{2}=N O+N\left\{\begin{array}{c}
k_{f 1}=7.6 * 10^{13} \exp (-3800 / T) \\
k_{b 1}=1.6 * 10^{13}
\end{array}\right. \\
N+O_{2}=N O+O\left\{\begin{array}{c}
k_{f 2}=6.4 * 10^{9} \mathrm{~T} \exp (-3150 / T) \\
k_{b 2}=1.5 * 10^{9} \mathrm{~T} \exp (-19500 / T)
\end{array}\right. \\
N+O H=N O+H\left\{\begin{array}{c}
k_{f 3}=4.1 * 10^{13} \\
k_{b 3}=2.0 * 10^{14} \exp (-23650 / T)
\end{array}\right. \\
\frac{d x_{i}}{d t}=\sum_{k=1}^{3}\left[k_{f k} \prod_{j=1}^{7} \tilde{x}_{j}^{\zeta f k, j}-k_{b k} \prod_{j=1}^{7} \tilde{x}_{j}^{\zeta b k j}\right] \quad(i=1, \ldots, 7)
\end{gathered}
$$

So, the results of this calculation procedure based on these models are illustrated in Fig. 8. It should be noted that the code simulates correctly (as shown in Table 9) the combustion process of the Capstone C30 for power levels above $22 \mathrm{~kW}$, when all three pilot solenoids are turned off and the premix solenoid is switched on.

Table 9: Prediction of dry NOx by simulation (MGTOFFDES Code)

Fig. 8: MGT C30 Emission Index NOx Map

The performances of Capstone C30 are investigated also varying the ambient temperature in a specific range and it is focused on its influence on the main operating parameters of the MGT. 
This analysis confirms that the MGT performance is greatly affected by its inlet air temperature, tied to ambient temperature. In other terms it endorses a significant limitation on the application of micro gas turbines, especially in hot climates $(\mathrm{T}=303.15 \mathrm{~K} / 313.15 \mathrm{~K})$, is strongly dependent of their performance, namely the power output and the thermal efficiency, on the ambient conditions. This inherent disadvantage can be mitigated by the reduction of MGT compressor inlet air temperature. This aspect is well represented in Fig.9, obtained identifying, for each ambient temperature, the performances (in terms of BSFC and NOx) of all operating points which are on the lines of the maximum power obtainable from the MGT, at that specific ambient temperature [41]. Increasing the ambient temperature, both the specific fuel consumption and the NOx emissions move to higher values. Instead, for a specific ambient temperature, if the specific fuel consumption increases, the NOx emissions decrease and vice versa. It is interesting to analyze the vehicle performances at a higher ambient temperature, where the operating conditions of the MGT are worse, in order to study this limit of the MGT in this application [42]. The operating point chosen for this analysis is shown in Fig. 9, and the MGT performances at this point are listed in Table 10.

Fig. 9. Influence of ambient temperature and MGT operating point chosen

Table 10: MGT performance at the point chosen in Fig. 9

Certainly one of the most important aspects of the MGT is the "Fuel Flexibility", so it is interesting to study the performances of the Capstone C30, when it is fueled by another fuel, in particular by Diesel fuel, using the same procedure followed for the case in which the MGT is fueled by Natural gas. So, only the main results of this study are presented here as shown in Fig. 10 and Fig. 11.

Fig. 10. MGT C30 BSFC Map-Diesel

Fig. 11. MGT C30 NOx Emission Index Map-Diesel 


\subsection{Diesel Engine}

The diesel engine used in this study is a $1.4 \mathrm{~L}$ engine with maximum power $50 \mathrm{~kW}$ at $3800 \mathrm{rpm}$ and maximum torque $180 \mathrm{Nm}$ at $2100 \mathrm{rpm}$ while its fuel consumption and NOx operating maps are presented at Fig. 12 and Fig. 13 respectively. It can be seen that there is a limited area where BSFC is minimized at $230 \mathrm{~g} / \mathrm{kWh}$.

Fig 12. Diesel engine BSFC map

Fig 13. Diesel engine NOx map

\section{Results \& Discussion}

\subsection{Range-Extended Electric Vehicle with MGT Supplied by Natural Gas [MGT1]}

Here the main simulation results of the REEV performances that have the Capstone Model C30 MicroTurbine as APU are presented. It is firstly analyzed the case in which the MGT is fueled by natural gas working in its nominal point at full load power and ISO conditions. It is presumed to calculate the $\mathrm{CO}$ emissions, and this information of Capstone $\mathrm{C} 30$ at operating conditions described are taken from the technical reference by Capstone. Eq. 18, Eq. 19, Eq. 20, Eq. 21 and Eq. 22 and used in order to have the NOx and CO cumulative emissions in [g], and the fuel mass consumption in $[\mathrm{kg}]$, at the end of the whole process.

$$
\begin{aligned}
& N O_{x}[\mathrm{~kg} / \mathrm{s}]=\frac{N O_{x}[\mathrm{ppm}] \cdot M W_{N O x} \cdot \text { Exhaust Mass Flow }[\mathrm{kg} / \mathrm{s}]}{M W_{\text {exh }} \cdot 10^{6}} \\
& C O[\mathrm{~kg} / \mathrm{s}]=\frac{C O[\mathrm{ppm}] \cdot M W_{C O} \cdot \text { Exhaust Mass Flow }[\mathrm{kg} / \mathrm{s}]}{M W_{\text {exh }} \cdot 10^{6}} \\
& N O_{x}[\mathrm{~g}]=\left(\int_{0}^{t_{\text {engine }}} \mathrm{NO} O_{x}[\mathrm{~kg} / \mathrm{s}] \cdot \mathrm{dt}\right) \times 1000 \\
& C O[\mathrm{~g}]=\left(\int_{0}^{t_{\text {engine }}} \mathrm{CO}[\mathrm{kg} / \mathrm{s}] \cdot \mathrm{dt}\right) \times 1000 \\
& \text { Fuel mass }[\mathrm{kg}]=\int_{0}^{t_{\text {engine }}} \text { Fuel consumption }[\mathrm{kg} / \mathrm{s}] \cdot d t
\end{aligned}
$$


Where $t_{\text {engine }}$ is the time for which the thermal engine is switched and $M W_{N O x}=46 \mathrm{~kg} / \mathrm{kmol}$, $M W_{C O}=28 \mathrm{~kg} / \mathrm{kmol}, M W_{\text {exh }}=29 \mathrm{~kg} / \mathrm{kmol}$. Fig. 14, Fig. 15, Fig. 16 and Fig. 17 represent the main results of the whole simulation process (for 10 NEDCs).

Fig. 14: Power from/into Battery-Output Power of MGT vs. Time

Fig. 15: Power during a single NEDC in which the MGT is switched-off

Fig. 16: Power during a single NEDC in which the MGT is switched-on

Fig. 17: State of Charge (SOC) vs. Time

Fig. 17 shows that SOC decreases until it reaches the minimum value imposed equal to 0.2. When this condition is reached, the MGT turns on and starts to charge the battery. In fact, starting from this point, the battery SOC begins to increase almost linearly. The MGT is switched on until the SOC of the battery reaches the maximum value imposed equal to 0.8. When this condition is reached the battery is considered fully charged and the MGT turns off. Table 11 shows the main vehicle performances at the end of the whole simulation process [20, $21,40,42-45]$.

Table 11: Major vehicle performances results from simulation of MGT1

\section{Range-Extended Electric Vehicle with MGT Supplied by Natural Gas, Operating at Higher Ambient Temperatures [MGT2]}

Previously it was validated that the performances of the MicroTurbine become worse when the ambient temperature increases, because the temperature of the compressor inlet air is higher. This is an important limit of the potential of the MGT, so it is interesting to study the disadvantages, the bad consequences, at which this limit can conduct in this specific application. It assumed to simulate the vehicle performances at ambient temperature of $303.15 \mathrm{~K}$, making the MicroTurbine work at operating conditions defined from the point for which the BSFC has the minimum value. The simulation results of this case are compared with the vehicle performances in the case Ambient $\mathrm{T}=288.15 \mathrm{~K}$, in Table 12 .

Table 12. Effect of different ambient temperature on performance of MGT2 
As expected, the vehicle performances, in terms of fuel consumption and NOx emissions, become worse when the ambient temperature increases.

\section{Range-Extended Electric Vehicle with MGT Supplied by Diesel Oil [MGT3]}

In this section the main simulation results of the REEV performance, with the MGT fueled by diesel oil working in its nominal point at full load power and ISO conditions are presented in Table 13. It can be clearly, in this case, seen that the nominal point of the MGT is different from that seen for gaseous fuel. It is interesting to make the comparison between the vehicle performances obtained with the MGT fueled by natural gas, and the vehicle performances obtained with the MGT fueled by diesel.

Table 13. Major vehicle performances results from simulation; MGT2 vs. MGT3

\section{Range-Extended Electric Vehicle with Diesel Engine (REVD)}

In this section the simulation results of the REEV in which the APU is a diesel engine, instead of the MGT, are presented in Table 14. Obviously it is necessary to choose a specific point on the engine operating maps to define the operating conditions of the engine inside the vehicle. So, in order to compare correctly the several proposed solutions, the operating point of the diesel engine must be chosen in such a way as to have an output power close to the power of the MGT that is around $30 \mathrm{~kW}$.

Table 14. Major vehicle performances results; compression between MGT3 and REEV with diesel engine

In particular an operating point on the power line of $30 \mathrm{~kW}$ for the best value of BSFC is selected. The simulation procedure for studying the vehicle performances is the same used for the case with MGT, so the simulation results, in terms of diagrams that show the trend of the vehicle speed, covered distance, SOC, fuel consumption etc., during the time are very similar to those ones previously seen. Here it is interesting to make the comparison between the vehicle performances obtained coupling the battery pack to a diesel engine and the vehicle performances when the APU is the MGT (fueled by diesel, so the fuel used for the two configurations is the same) $[28,41,42,46]$. 


\section{Conventional Diesel Vehicle (CD)}

In this section the simulation results for the conventional diesel vehicle, in terms of fuel consumption and NOx cumulative emissions are shown and compared with the performances of the range extender hybrid vehicle with diesel engine as seen in Table 15.

Table 15. Major vehicle performances results; compression between REEV with diesel engine and conventional diesel vehicle

It is worth to mention that the simulation results of the conventional vehicle have to be considered as indexes of the magnitude order of these parameters. In fact it can be expected that the real values are higher than these ones obtained with the calculation seen, because of two main approximations of the simulation process: the engine transient conditions and the cold-start of the engine. So it can be expected that the real values of the vehicle performances are grater of 20-30\% than those ones shown in the table above.

\section{Sensitivity Analysis}

The main goal of this analysis is to study what impact the variation of the vehicle mass or the battery capacity has on the performances of the REEV in terms of fuel consumption. The analysis is made for the REEV with MGT fueled by natural gas. The results are shown in Fig. 18 and Fig. 19.

Fig. 18: Sensitivity analysis for the vehicle mass

Fig. 19: Sensitivity analysis for the battery capacity (Matlab)

Fig. 18 confirms what expected as the fuel consumption of the vehicle increases with the vehicle mass. Fig. 19 shows that in the area of low values of the battery capacity, a small increase of this one causes a significant decrease of the fuel consumption. Instead, going to high values of the battery capacity, the fuel consumption is almost constant with it. 


\section{Conclusions}

The main purpose of this work was to analyze the potential of Micro Gas Turbines (MGT) to be used as Auxiliary Power Unit (APU) for Range-Extended Electric Vehicles (REEV). The work presented an assessment of a novel hybrid configuration comprising a MGT, a battery pack, and a traction electric motor, by mainly focusing the attention on its potential contribution to the reduction in fuel consumption and pollutant emissions, respect to equivalent diesel or gasoline hybrid propulsion units or to conventional diesel vehicle. Several cases study were defined and simulated, so that a complete comparison among them can be outlined in Table 16.

Table 16. Overall comparable results of vehicle performances in different cases

If making reference to an average cost of the two fuels used, a short analysis of the costs can also be made, as shown in Table 19. Fuel Cost-Natural gas: 0.981 €/kg and Fuel Cost-Diesel oil: $1.238 € / 1$.

Table 17. Average cost of Natural Gas and Diesel Oil fuels used in different cases

Both Tables 16 and Table 17 imply that the use of the MGT for REEV applications suggests important and attractive results in terms of NOx and CO emissions. Instead, in terms of fuel consumption, the competitiveness of this solution respect to the REEV with diesel engine and to the conventional diesel vehicle, much depends on the operating conditions of the MGT and on the fuel supplied. The sensitivity analysis outlines that the fuel consumption of the hybrid vehicle with MGT is much influenced also by the vehicle mass and the battery capacity. It has been also showed the strong influence of the ambient temperature on the MGT performances, and the case study MGT2 outlines the impact of this limit of the MGT on the performances of the whole vehicle. At last, it is interesting to present possible and attractive future developments of the technology proposed and of the research work:

- The sensitivity of the results, in terms of fuel consumption and NOx emissions, to the battery capacity means that improvements of this characteristic will lead better performances of the technology proposed and analyzed. 
- The approach and the method used for calculating the vehicle performances can be improved, attempting to simulate the transient conditions of the engine in the conventional vehicle and also to include Worldwide Harmonized Light Vehicle Test Procedure (WLTP) beside of NEDC test procedure.

- As already said, it could be interesting to analyze the influence of the ambient temperature also on the performances of the MGT supplied with diesel oil.

- The REEV technology with MGT is certainly an interesting solution, in the transition to the "fully electric vehicle", which will be a real alternative to the conventional diesel or gasoline vehicles only when it will be possible to charge the battery on the board in a suitable way at electric charging stations.

\section{References}

[1] Guzzella L, Sciarretta A, Springer-Verlag Gmb H. Vehicle Propulsion Systems Introduction to Modeling and Optimization. Berlin: Springer Berlin, 2015.

[2] Tuccillo R. Performance and transient behaviour of MTG based energy systems. VKI/LS on "Micro Gas Turbines," RTO-MP-AVT-131. 2005.

[3] Arav B, Shulman R, Dooun V. Basic Concepts for Forcing of Low-Power Micro Turbine Generators. Procedia Engineering. 2016;150:1384-90.

[4] Arav BL, Shulman R, Kozminykh VA. Refinement of Hybrid Motor-transmission Set Using Micro Turbine Generator. Procedia Engineering. 2015;129:166-70.

[5] Christodoulou F, Giannakakis P, Kalfas AI. Performance Benefits of a Portable Hybrid Micro-Gas Turbine Power System for Automotive Applications. Journal of Engineering for Gas Turbines and Power. 2010;133(2):022301--8.

[6] Feneley AJ, Pesiridis A, Mahmoudzadeh Andwari A. Variable Geometry Turbocharger Technologies for Exhaust Energy Recovery and Boosting- A Review. Renewable and Sustainable Energy Reviews. 2017;71:959-75.

[7] Ghanaati A, Mat Darus IZ, Farid M, Said M, Mahmoudzadeh Andwari A. A Mean Value Model For Estimation Of Laminar And Turbulent Flame Speed In Spark-Ignition Engine. International Journal of Automotive and Mechanical EngineeringOnline. 2015;11:2229-8649.

[8] Mahmoudzadeh Andwari A, Pesiridis A, Karvountzis-Kontakiotis A, Esfahanian V. Hybrid electric vehicle performance with organic rankine cycle waste heat recovery system. Appl Sci. 2017;7(5).

[9] Mahmoudzadeh Andwari A, Pesiridis A, Esfahanian V, Salavati-Zadeh A, KarvountzisKontakiotis A, Muralidharan V. A Comparative Study of the Effect of Turbocompounding and 
ORC Waste Heat Recovery Systems on the Performance of a Turbocharged Heavy-Duty Diesel Engine. Energies. 2017;10(8):1087.

[10] Mahmoudzadeh Andwari A, Pesiridis A, Rajoo S, Martinez-Botas R, Esfahanian V. A review of Battery Electric Vehicle technology and readiness levels. Renewable and Sustainable Energy Reviews. 2017;78:414-30.

[11] Spentzas SN. Benefits and Applications of Small-scale and Micro-CHP Systems. Cogeneration \& Distributed Generation Journal. 2008;23(2):6-34.

[12] Tuccillo R, Cameretti MC. Combustion and Combustors for MGT Applications. Micro Gas Turbines. 2005:1-56.

[13] Turkeli-Ramadan Z, Sharma RN, Raine RR. Experimental Study on Flat Flame Combustion for Ultra Micro Gas Turbine Applications. Combustion Science and Technology. 2017;189(8):1307-25.

[14] Yamada T, Asako Y. Scale Effect on Gaseous Flow around a Micro-Scaled Gas Turbine Blade. Heat Transfer Engineering. 2007;28(8-9):696-703.

[15] Abagnale C, Cameretti MC, De Robbio R, Tuccillo R. CFD Study of a MGT Combustor Supplied with Syngas. Energy Procedia. 2016;101:933-40.

[16] Almasi A. Bright future of micro-turbines: Nuclear emergency cooling and miniature generator. Australian Journal of Mechanical Engineering. 2013;11(2):169-75.

[17] Bakalis DP, Stamatis AG. Performance Simulation of a Hybrid Micro Gas Turbine Fuel Cell System Based on Existing Components. 2011(54648):171-9.

[18] Chen L, Zhang W, Sun F. Thermodynamic optimization for an open cycle of an externally fired micro gas turbine (EFmGT). Part 1: Thermodynamic modelling. International Journal of Sustainable Energy. 2011;30(4):246-56.

[19] Mahmoudzadeh Andwari A, Aziz AA, Muhamad Said MF, Abdul Latiff Z. Controlled Auto-Ignition Combustion in a Two-Stroke Cycle Engine Using Hot Burned Gases. Applied Mechanics and Materials. 2013;388:201-5.

[20] Mahmoudzadeh Andwari A, Aziz AA, Said MFM, Latiff ZA. A Converted Two-Stroke Cycle Engine for Compression Ignition Combustion. Applied Mechanics and Materials. 2014;663:331-5.

[21] Mahmoudzadeh Andwari A, Aziz AA, Said MFM, Latiff ZA. Experimental investigation of the influence of internal and external EGR on the combustion characteristics of a controlled autoignition two-stroke cycle engine. Applied Energy. 2014;134:1-10.

[22] Harrison J. Micro combined heat and power (CHP) systems for residential and small commercial buildings A2 - Beith, Robert. Small and Micro Combined Heat and Power (CHP) Systems: Woodhead Publishing; 2011. p. 325-46.

[23] Judge AW. Small Gas Turbines And Free Piston Engines: Springer US, 1960.

[24] Jurado F, Ortega M, Cano A. Predictive Control of Matrix Converter-based Micro-turbine. Electric Power Components and Systems. 2008;36(4):409-31.

[25] Lee YB, Kwak HD, Kim CH, Jang GH. Analysis of Gas-Lubricated Bearings with a Coupled Boundary Effect for Micro Gas Turbine. Tribology Transactions. 2001;44(4):685-91. 
[26] Larminie J, Lowry J. Electric Vehicle Technology Explained: John Wiley \& Sons, Inc., 2004.

[27] Larminie J, Lowry J. Electric Vehicle Technology Explained, Second Edition. Second Edition ed: John Wiley \& Sons, Inc., 2012.

[28] Riffat SB, Zhao X, Doherty PS. Investigation of the flow in an impulse micro turbine using numerical CFD predictions and laboratory testing. International Journal of Ambient Energy. 2002;23(4):171-8.

[29] Comodi G, Renzi M, Caresana F, Pelagalli L. Limiting the Effect of Ambient Temperature on Micro Gas Turbines (MGTs) Performance Through Inlet Air Cooling (IAC) Techniques: An Experimental Comparison between Fogging and Direct Expansion. Energy Procedia.

2015;75:1172-7.

[30] Corporation CT. Technical Reference Capstone Model C30 Performance. USA: Capstone Turbine Corporation; 2006.

[31] De Paepe W, Sayad P, Bram S, Klingmann J, Contino F. Experimental Investigation of the Effect of Steam Dilution on the Combustion of Methane for Humidified Micro Gas Turbine Applications. Combustion Science and Technology. 2016;188(8):1199-219.

[32] Hu X, Li S, Peng H. A comparative study of equivalent circuit models for $\mathrm{Li}$-ion batteries. Journal of Power Sources. 2012;198(Supplement C):359-67.

[33] Huang WS, Tzeng KE, Cheng MC, Huang RS. A silicon mems micro power generator for wearable micro devices. Journal of the Chinese Institute of Engineers. 2007;30(1):133-40.

[34] Giovannoni V, Sharma RN, Raine RR. Thermal Performances of a Small Scale Regenerative Combustion Chamber for Ultra Micro Gas Turbine. Combustion Science and Technology. 2017:null-null.

[35] Gopisetty S, Treffinger P. Generic Combined Heat and Power (CHP) Model for the Concept Phase of Energy Planning Process. Energies. 2017;10(1):11.

[36] Mahmoudzadeh Andwari A, Abdul Aziz A, Muhamad Said MF, Abdul Latiff Z. An experimental study on the influence of EGR rate and fuel octane number on the combustion characteristics of a CAI two-stroke cycle engine. Applied Thermal Engineering. 2014;71(1):24858 .

[37] Mahmoudzadeh Andwari A, Aziz AA, Said MFM, Latiff ZA, Ghanaati A. Influence Of Hot Burned Gas Utilization On The Exhaust Emission Characteristics Of A Controlled Auto-Ignition Two-Stroke Cycle Engine. International Journal of Automotive and Mechanical EngineeringOnline. 2015;11:2229-8649.

[38] Said MFM, Aziz ABA, Latiff ZA, Mahmoudzadeh Andwari A, Soid SNM. Investigation of Cylinder Deactivation (CDA) Strategies on Part Load Conditions. SAE Technical Paper 201401-2549. 2014.

[39] Sim K, Koo B, Kim CH, Kim TH. Development and performance measurement of micropower pack using micro-gas turbine driven automotive alternators. Applied Energy. 2013;102:309-19. 
[40] Sogut MZ. Exergetic Irreversibility and Sustainability Performances for Alternative Fuels in the Micro-Turbojet Engine. International Journal of Green Energy. 2017:1-12.

[41] Mozafari A, Ehyaei MA. Effects of Regeneration Heat Exchanger on Entropy, Electricity Cost, and Environmental Pollution Produced by Micro Gas Turbine System. International Journal of Green Energy. 2012;9(1):51-70.

[42] Rahman MM, Ibrahim TK, Kadirgama K, Mamat R, Bakar RA. Influence of Operation Conditions and Ambient Temperature on Performance of Gas Turbine Power Plant. Advanced Materials Research. 2011;189-193:3007-13.

[43] Jiang L, Zhao D, Yamashita H. Study on a Lower Heat Loss Micro Gas Turbine Combustor with Porous Inlet. Combustion Science and Technology. 2015;187(9):1376-91.

[44] Kulshreshtha DB, Channiwala SA. Hydrogen Fuelled Micro Gas Turbine Combustion Chamber. HKIE Transactions. 2011;18(2):19-25.

[45] Mahmoudzadeh Andwari A, Azhar AA. Homogenous Charge Compression Ignition (HCCI) Technique: A Review for Application in Two-Stroke Gasoline Engines. Applied Mechanics and Materials. 2012;165:53-7.

[46] Ribau J, Silva C, Brito FP, Martins J. Analysis of four-stroke, Wankel, and microturbine based range extenders for electric vehicles. Energy Conversion and Management. 2012;58:12033. 
Tables:

Table 1: Coefficients used for electrical power of motor

\begin{tabular}{ccc}
\hline Coefficients & Names & Values \\
\hline$k_{c}$ & Copper loss coefficient. & 0.3 \\
$k_{i}$ & Iron loss coefficient & 0.01 \\
$k_{w}$ & Windage loss coefficient & $5.0 \cdot 10^{-6}$ \\
$C$ & Constant loss coefficient & 600 \\
\hline
\end{tabular}

Table 2: Main REEV parameters

\begin{tabular}{lc}
\hline Parameters & Values \\
\hline Coefficient of rolling resistance $\mu_{r r}$ & 0.005 \\
Drag coefficient $C_{d}$ & 0.19 \\
Frontal area & $2.6 \mathrm{~m}^{2}$ \\
Vehicle mass & $1500-2000 \mathrm{~kg}$ \\
Transmission efficiency $\eta_{\text {trans }}$ & 0.95 \\
Gearing ratio $(\mathrm{G} / \mathrm{r})$ & 40 \\
\hline
\end{tabular}

Table 3: Diesel car main parameters.

\begin{tabular}{lc}
\hline Parameters & Values \\
\hline Vehicle mass $[\mathrm{kg}]$ & 1110 \\
Frontal Area $\left[\mathrm{m}^{3}\right]$ & 2.5 \\
Drag coefficient $[-]$ & 0.29 \\
Differential Ratio & 3.65 \\
Differential Efficiency & 0.99 \\
\hline
\end{tabular}

Table 4: Diesel car transmission characteristics

\begin{tabular}{cccc}
\hline $\begin{array}{c}\text { Vehicle Speed } \\
{[\mathbf{k m} / \mathbf{h}]}\end{array}$ & $\begin{array}{c}\text { Gear } \\
\text { Shifting }\end{array}$ & $\begin{array}{c}\text { Gear } \\
\text { Ratio }\end{array}$ & $\begin{array}{c}\text { Gear } \\
\text { Efficiency }\end{array}$ \\
\hline 0 & 1 & 3.54 & 0.99 \\
15 & 2 & 1.85 & 0.99 \\
32 & 3 & 1.3 & 0.99 \\
50 & 4 & 0.95 & 0.99 \\
70 & 5 & 0.7 & 0.99 \\
100 & 6 & 0.5 & 0.99 \\
\hline
\end{tabular}


Table 5: MGT cycle design point claimed from Capstone Turbine Corporation

\begin{tabular}{lc}
\hline Performance & Natural gas fuel \\
\hline Rated Output $[\mathrm{kW}]$ & $30.0( \pm 1)$ \\
Thermal Efficiency $[\%]$ & $26.0( \pm 2)$ \\
Exhaust Mass Flow $[\mathrm{kg} / \mathrm{s}]$ & 0.31 \\
Exhaust Temperature $\left[{ }^{0} \mathrm{C}\right]$ & 275 \\
Fuel Flow $(\mathrm{LHV}$ Based) $[\mathrm{kJ} / \mathrm{h}]$ & 415000 \\
Rotational Speed $[\mathrm{rpm}]$ & 96000 \\
\hline
\end{tabular}

Table 6: Performance parameters comparison between simulated MGT and base Capstone MGT

\begin{tabular}{lccc}
\hline Performance & Capstone & GASTURB & Error [\%] \\
\hline Rated Output [kW] & $30.0(+0 /-1)$ & 29.8 & -0.6 \\
Thermal Efficiency [\%] & $26.0( \pm 2)$ & 26.2 & 0.77 \\
Exhaust Mass Flow [kg/s] & 0.31 & 0.31 & 0 \\
Exhaust Temperature [ $\left.{ }^{0} \mathrm{C}\right]$ & 275 & 267 & -2.9 \\
Fuel Flow (LHV Based) [kJ/h] & 415000 & 409855 & -1.23 \\
Rotational Speed [rpm] & 96000 & 96000 & 96000 \\
\hline
\end{tabular}

Table 7: Off-Design parameters analysis of MicroTurbine

\begin{tabular}{lcc}
\hline Parameters & Turbine Inlet Temp & Relative Rotational Speed \\
\hline Start Value & $945 \mathrm{~K}$ & $0.7(67200 \mathrm{rpm})$ \\
Number of Values & 18 & 11 \\
Step Size & $15 \mathrm{~K}$ & 0.04 \\
End Value & $1200 \mathrm{~K}$ & $1.1(105600 \mathrm{rpm})$ \\
\hline
\end{tabular}

Table 8: Theoretical approach developed through Off-Design procedure

\begin{tabular}{lc}
\hline Formulations & Procedure of calculation \\
\hline$\beta_{c}, \eta_{c}=f\left(\dot{m}_{a}, N, T_{1}, p_{1}\right)$ & Compressor Map Accessed \\
$T_{2}, p_{2}, h_{2}, \ldots=f\left(\beta_{c}, \eta_{c}, T_{1}, p_{1}\right)$ & Compression Calculation \\
$T_{2 R}, p_{2 R}, h_{2 R}, \ldots=f\left(T_{2}, p_{2}, \eta_{r e c}, \varepsilon_{r e c}\right)$ & Recuperator Calculation \\
$T_{3}, p_{3}, h_{3}, \ldots=f\left(\dot{m}_{a}, \dot{m}_{f}, \eta_{c}, T_{2}, p_{2}, h_{2}, \eta_{b}, \varepsilon_{c c}\right)$ & Combustion Calculation \\
$\beta_{t}, \eta_{t}=f\left(\dot{m}_{a}+\dot{m}_{f}, N, T_{3}, p_{3}\right)$ & Turbine Map Accessed \\
$T_{4}, p_{4}, h_{4}=f\left(\beta_{t}, \eta_{t}, T_{3}, p_{3}\right)$ & Expansion Calculation \\
\hline
\end{tabular}


Table 9: Prediction of dry NOx by simulation (MGTOFFDES Code)

\begin{tabular}{lccc}
\hline \multicolumn{3}{c}{ Design points } \\
\hline Performance & Capstone & MGTOFFDES Code & Error [\%] \\
\hline Dry NOx [ppm] & 9 & 8.83 & -1.88 \\
\hline
\end{tabular}

Table 10: MGT performance at the point chosen in Fig. 9

\begin{tabular}{lc}
\hline Performance & Value \\
\hline Rated Output $[\mathrm{kW}]$ & 25 \\
Exhaust Mass Flow $[\mathrm{kg} / \mathrm{s}]$ & 0.278 \\
NOx [ppm] & 9.2 \\
Fuel Consumption $[\mathrm{kg} / \mathrm{s}]$ & 0.00213 \\
Specific Fuel Consumption $[\mathrm{g} /(\mathrm{kW} \cdot \mathrm{h})]$ & 306 \\
\hline
\end{tabular}

Table 11: Major vehicle performances results from simulation of MGT1

\begin{tabular}{ccc}
\hline Performances & \multicolumn{3}{c}{ Results } \\
\hline MGT Time ON $[\mathrm{s}]$ & \multicolumn{3}{c}{2152} \\
\hline & $($ Per 100 km) & (Per km) \\
Fuel Consumption $[\mathrm{kg}]$ & 4.84 & 0.048 \\
$\mathrm{CO}_{2}[\mathrm{~g}]$ & 11784 & 117.8 \\
$\mathrm{NO}_{x}[\mathrm{~g}]$ & 5.81 & 0.058 \\
$\mathrm{CO}[\mathrm{g}]$ & 23.58 & 0.236 \\
\hline
\end{tabular}

Table 12. Effect of different ambient temperature on performance of MGT2

\begin{tabular}{lcc}
\hline \multirow{2}{*}{ Performances } & \multicolumn{2}{c}{ Results } \\
\cline { 2 - 3 } & Ambient $\mathbf{T}=\mathbf{2 8 8 . 1 5} \mathbf{~ K}$ & Ambient T=303.15 K \\
\hline MGT Time $[\mathrm{s}]$ & 2152 & 2589 \\
Fuel Consumption $[\mathrm{kg} / 100 \mathrm{~km}]$ & 4.84 & 5.05 \\
$\mathrm{CO}_{2}[\mathrm{~g} / 100 \mathrm{~km}]$ & 11784 & 12296 \\
$\mathrm{NO}_{x}[\mathrm{~g} / 100 \mathrm{~km}]$ & 5.81 & 9.60 \\
\hline
\end{tabular}


Table 13. Major vehicle performances results from simulation; MGT2 vs. MGT3

\begin{tabular}{lcc}
\hline \multirow{2}{*}{ Performances } & \multicolumn{2}{c}{ Results } \\
\cline { 2 - 3 } & Natural gas & Diesel oil \\
\hline Fuel Consumption $[\mathrm{kg} / 100 \mathrm{~km}]$ & 4.84 & 5.39 \\
Fuel Consumption $[1 / 100 \mathrm{~km}]$ & - & 6.41 \\
$\mathrm{CO}_{2}[\mathrm{~g} / 100 \mathrm{~km}]$ & 11784 & 16987 \\
$\mathrm{NO} O_{x}[\mathrm{~g} / 100 \mathrm{~km}]$ & 5.81 & 30.9 \\
$\mathrm{CO}[\mathrm{g} / 100 \mathrm{~km}]$ & 23.58 & 5.46 \\
Fuel Cost & $0.981 € / \mathrm{kg}$ & $1.238 € / 1$ \\
$€ / 100 \mathrm{~km}$ & 4.75 & 7.93 \\
\hline
\end{tabular}

Table 14. Major vehicle performances results; compression between MGT3 and REEV with diesel engine

\begin{tabular}{lcc}
\hline \multicolumn{1}{c}{ Performances } & \multicolumn{2}{c}{ Results } \\
\cline { 2 - 3 } & Diesel engine & MGT fueled by diesel oil \\
\hline Fuel Consumption $[\mathrm{kg} / 100 \mathrm{~km}]$ & 3.66 & 5.39 \\
Fuel Consumption $[1 / 100 \mathrm{~km}]$ & 4.31 & 6.41 \\
$\mathrm{CO}_{2}[\mathrm{~g} / 100 \mathrm{~km}]$ & 11422 & 16987 \\
$\mathrm{NO}_{x}[\mathrm{~g} / 100 \mathrm{~km}]$ & 151.2 & 30.9 \\
$\mathrm{CO}[\mathrm{g} / 100 \mathrm{~km}]$ & 68.15 & 5.46 \\
Fuel Cost & $1.238 € / 1$ & $1.238 € / 1$ \\
$€ / 100 \mathrm{~km}$ & 5.33 & 7.93 \\
\hline
\end{tabular}

Table 15. Major vehicle performances results; compression between REEV with diesel engine and conventional diesel vehicle

\begin{tabular}{lcc}
\hline \multicolumn{1}{c}{ Performances } & \multicolumn{2}{c}{ Results } \\
\cline { 2 - 3 } & REEV with Diesel & Conventional diesel vehicle \\
\hline Fuel Consumption $[\mathrm{kg} / 100 \mathrm{~km}]$ & 3.66 & 3.98 \\
Fuel Consumption $[1 / 100 \mathrm{~km}]$ & 4.31 & 4.68 \\
$\mathrm{CO}_{2}[\mathrm{~g} / 100 \mathrm{~km}]$ & 11422 & 12397 \\
$\mathrm{NO}_{x}[\mathrm{~g} / 100 \mathrm{~km}]$ & 151.2 & 39.72 \\
Fuel Cost & $1.238 € / 1$ & $1.238 € / 1$ \\
$€ / 100 \mathrm{~km}$ & 5.33 & 5.8 \\
\hline
\end{tabular}


Table 16. Overall comparable results of vehicle performances in different cases

\begin{tabular}{cccccc}
\hline $\begin{array}{c}\text { Case } \\
\text { Study }\end{array}$ & $\begin{array}{c}\text { Fuel consumption } \\
{[\mathbf{k g} / \mathbf{1 0 0} \mathbf{~ k m}]}\end{array}$ & $\begin{array}{c}\text { Fuel consumption } \\
{[\mathbf{1} / \mathbf{1 0 0} \mathbf{~ k m}]}\end{array}$ & $\begin{array}{c}\mathbf{C O}_{\mathbf{2}} \\
{[\mathbf{g} / \mathbf{1 0 0} \mathbf{k m}]}\end{array}$ & $\begin{array}{c}\mathbf{N O}_{\boldsymbol{x}} \\
{[\mathbf{g} / \mathbf{1 0 0} \mathbf{k m}]}\end{array}$ & $\begin{array}{c}\mathbf{C O} \\
{[\mathbf{g} / \mathbf{1 0 0} \mathbf{~ k m}]}\end{array}$ \\
\hline MGT1 & 4.84 & - & 11784 & 5.81 & 23.58 \\
MGT2 & 5.05 & - & 12296 & 9.60 & - \\
MGT3 & 5.39 & 6.41 & 16987 & 30.9 & 5.46 \\
REVD & 3.66 & 4.31 & 11422 & 151.2 & 68.15 \\
CD & 3.98 & 4.68 & 12398 & 39.72 & - \\
\hline
\end{tabular}

Table 17. Average cost of Natural Gas and Diesel Oil fuels used in different cases

\begin{tabular}{cccccc}
\hline & MGT1 & MGT2 & MGT3 & REVD & CD \\
\hline $\boldsymbol{\epsilon} / \mathbf{1 0 0} \mathbf{~ k m}$ & 4.74 & 4.95 & 7.93 & 5.33 & 5.79 \\
\hline
\end{tabular}




\section{Figures:}

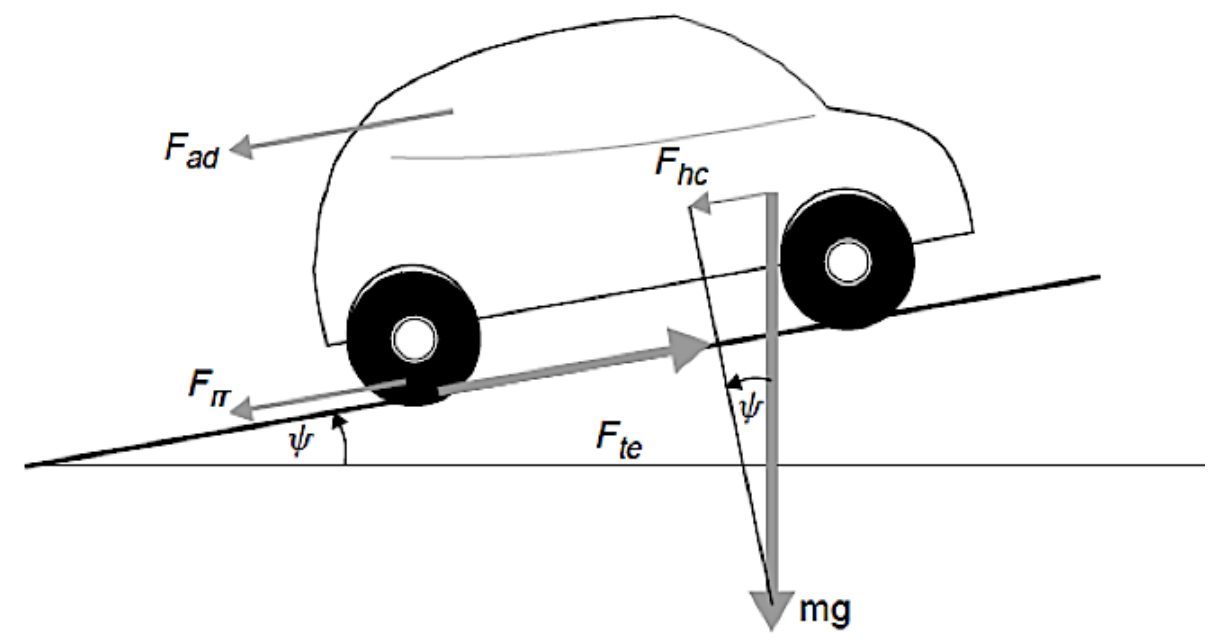

Fig. 2: Schematic representation for uphill driving [26]

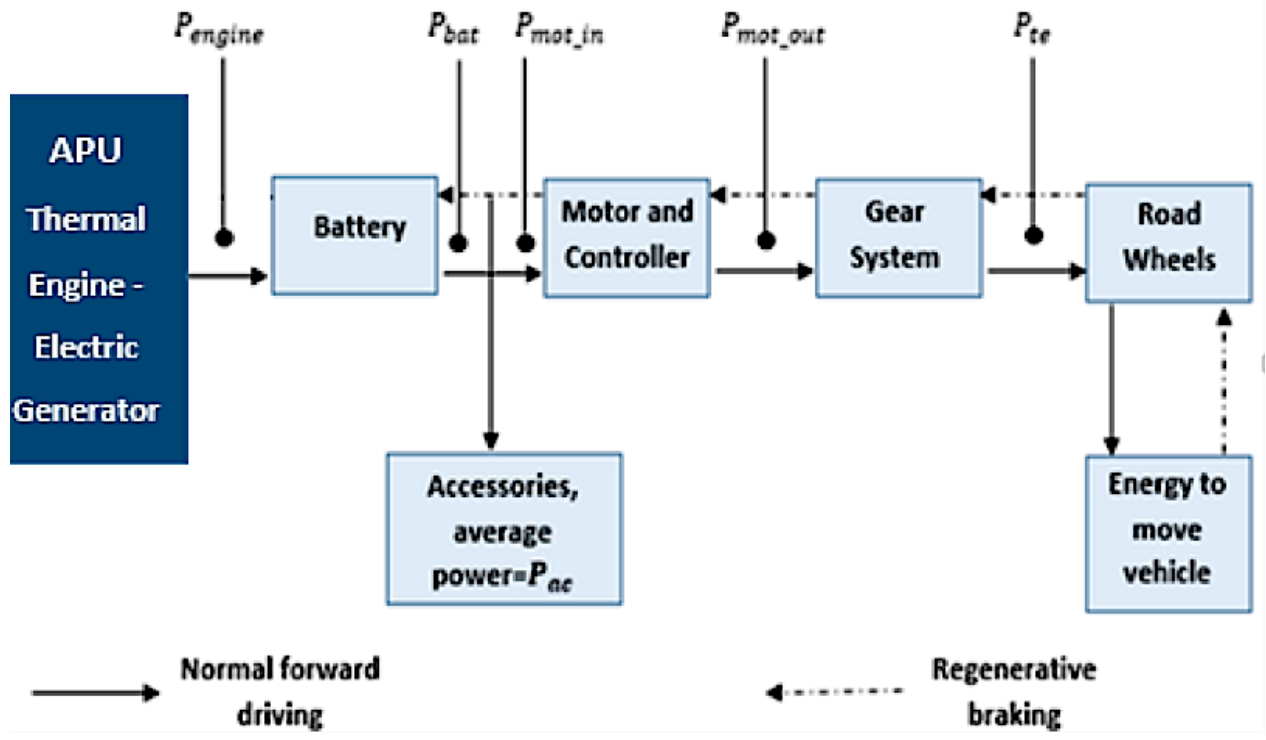

Fig. 2: Energy flows in the vehicle 


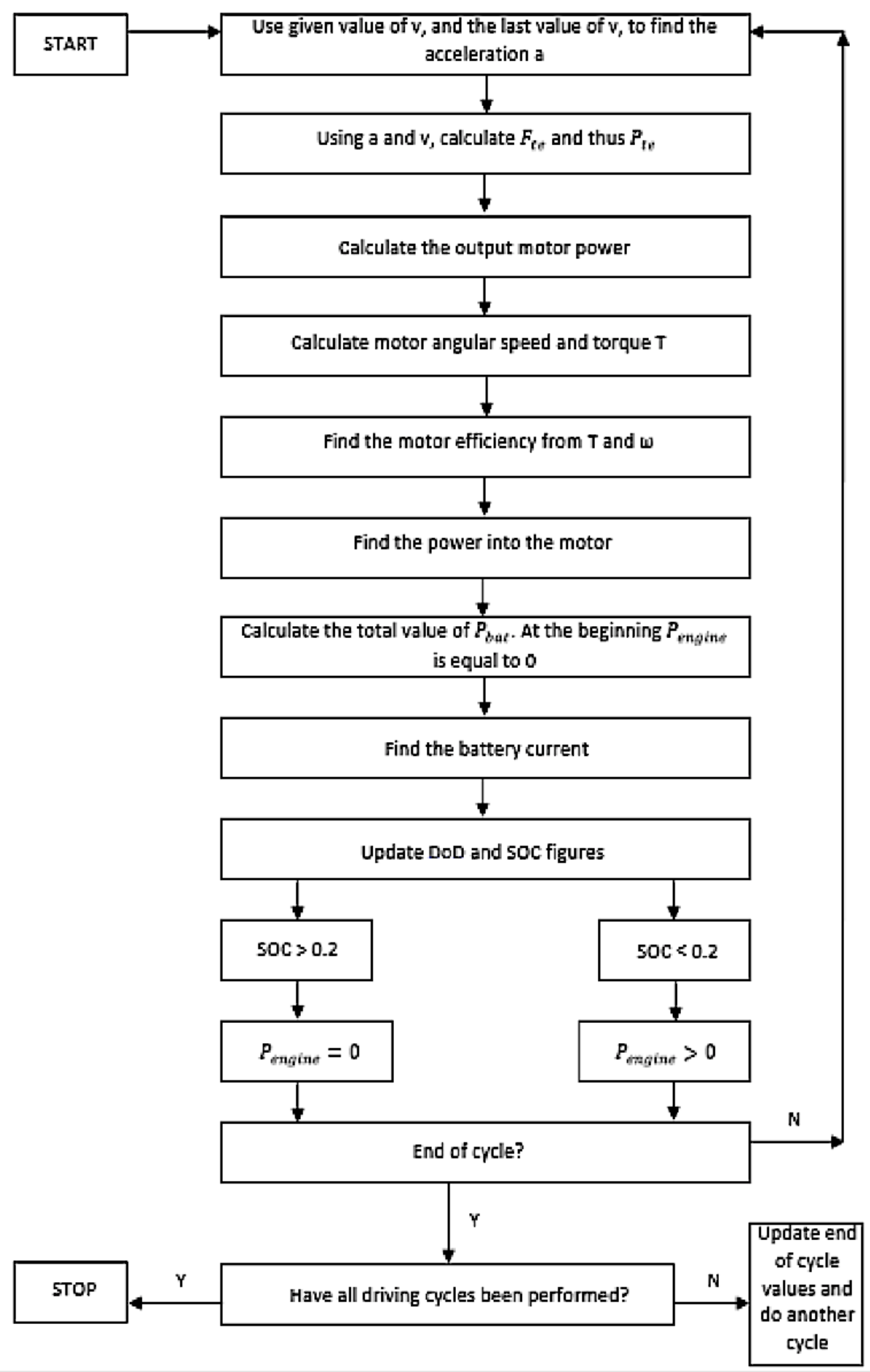

Fig. 3: Flowchart for the simulation of Range-Extended Electric Vehicle (REEV) 


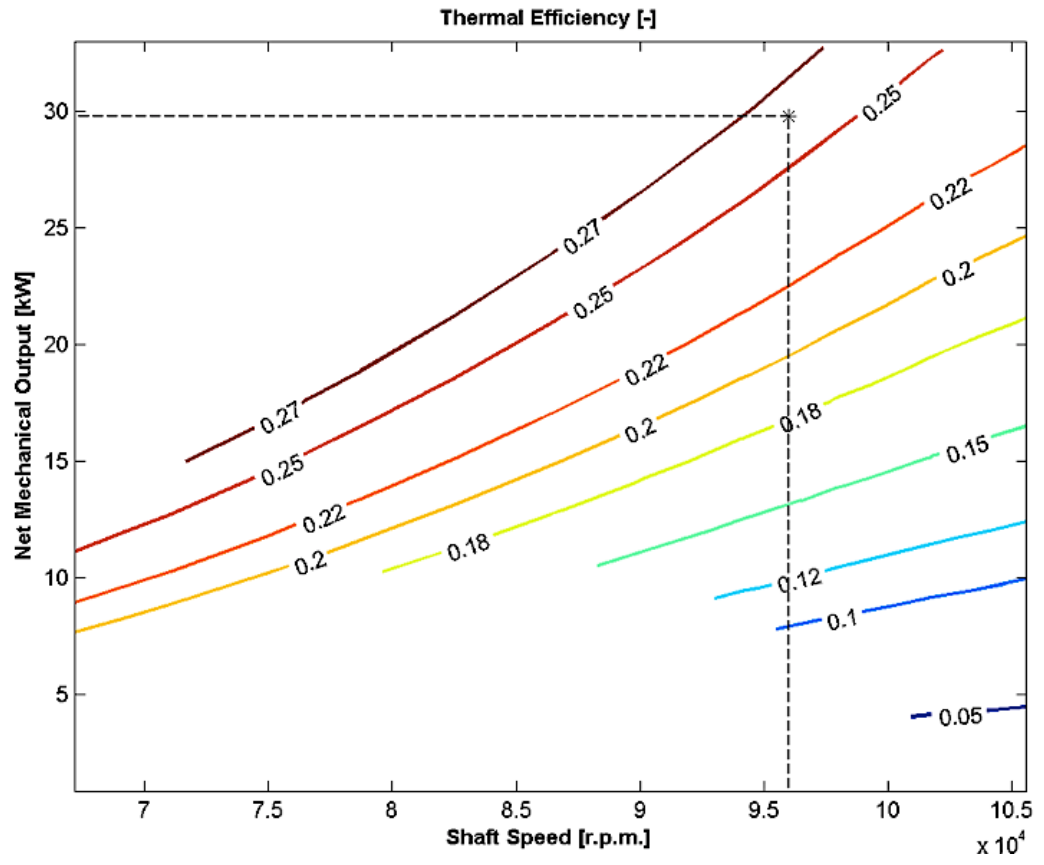

Fig. 4: MGT C30 Thermal Efficiency Map

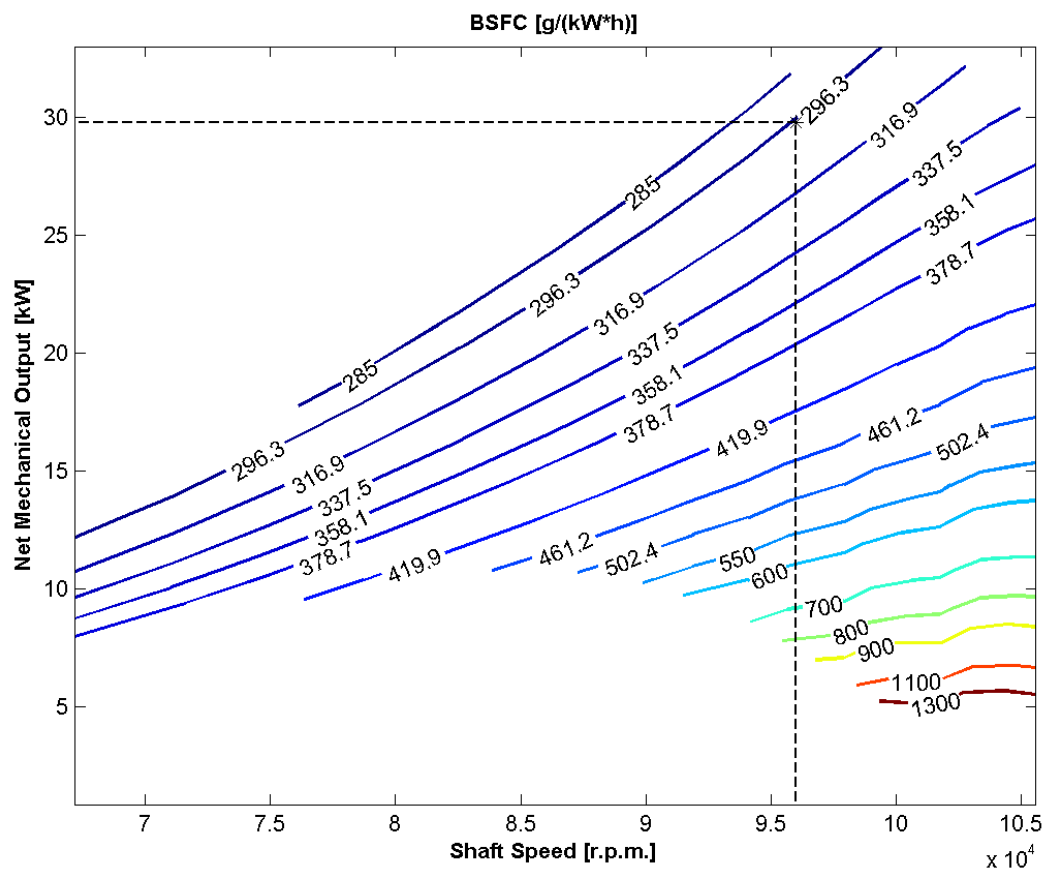

Fig. 5: MGT C30 Brake Specific Fuel Consumption (BSFC) Map 


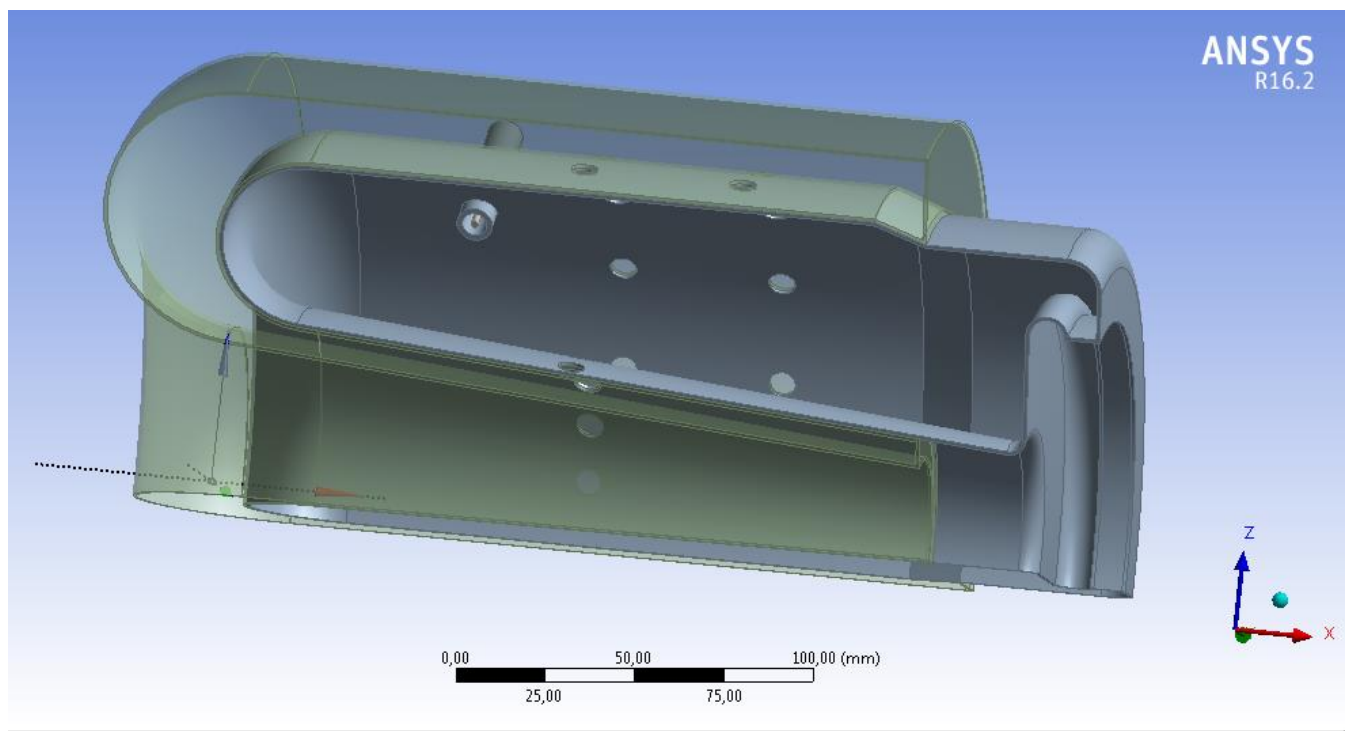

Fig. 6: MGT C30 combustion chamber for gaseous fuel

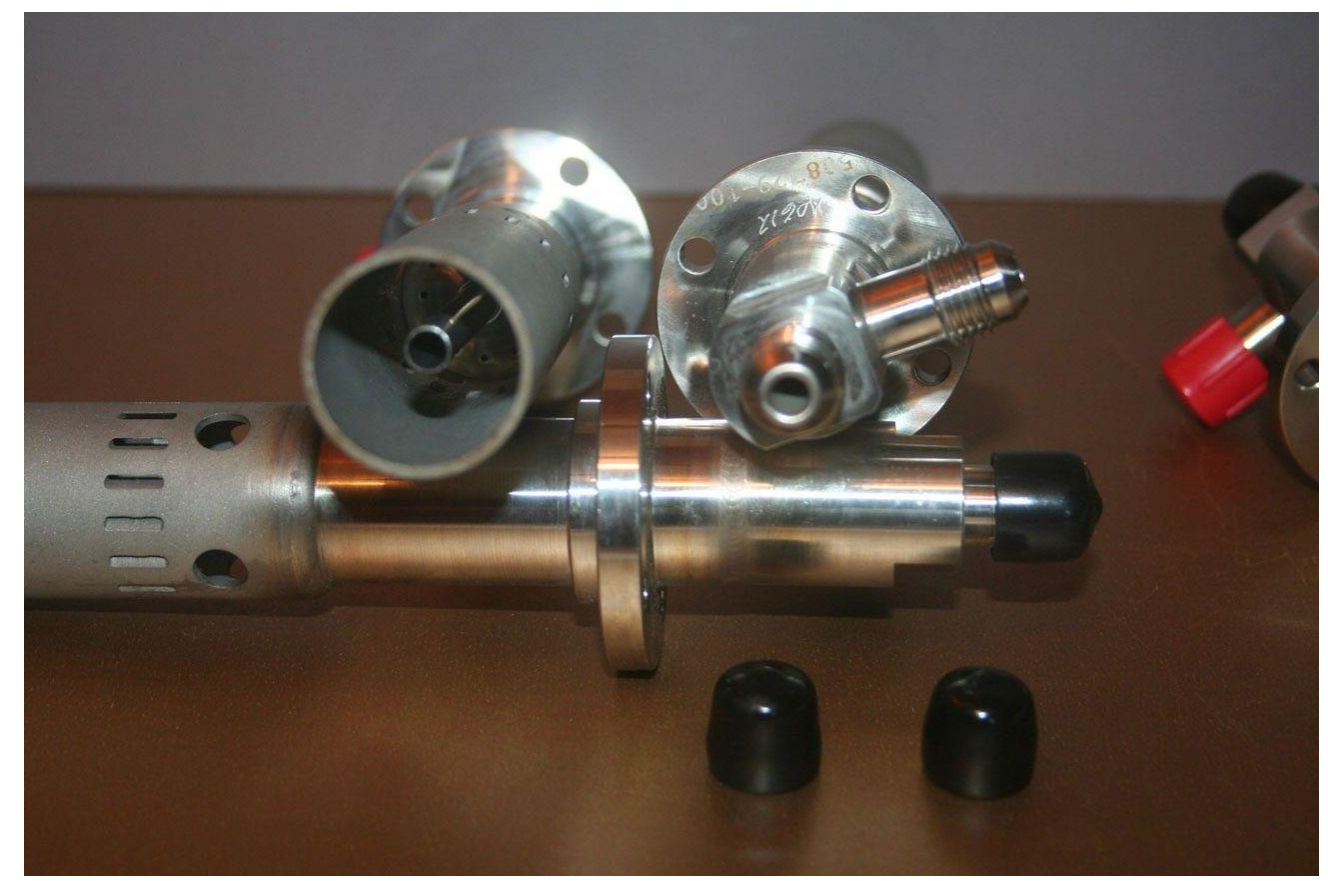

Fig. 7: MGT C30 Fuel Injectors 


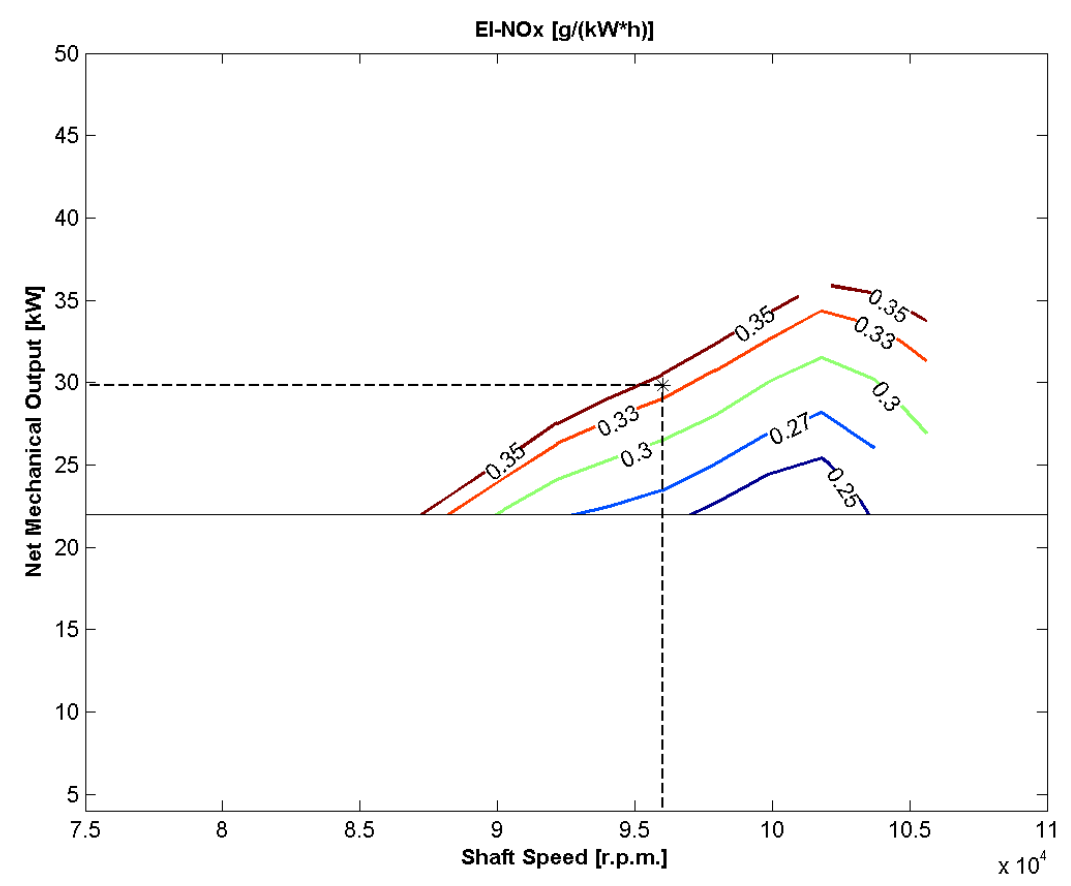

Fig. 8: MGT C30 Emission Index NOx Map

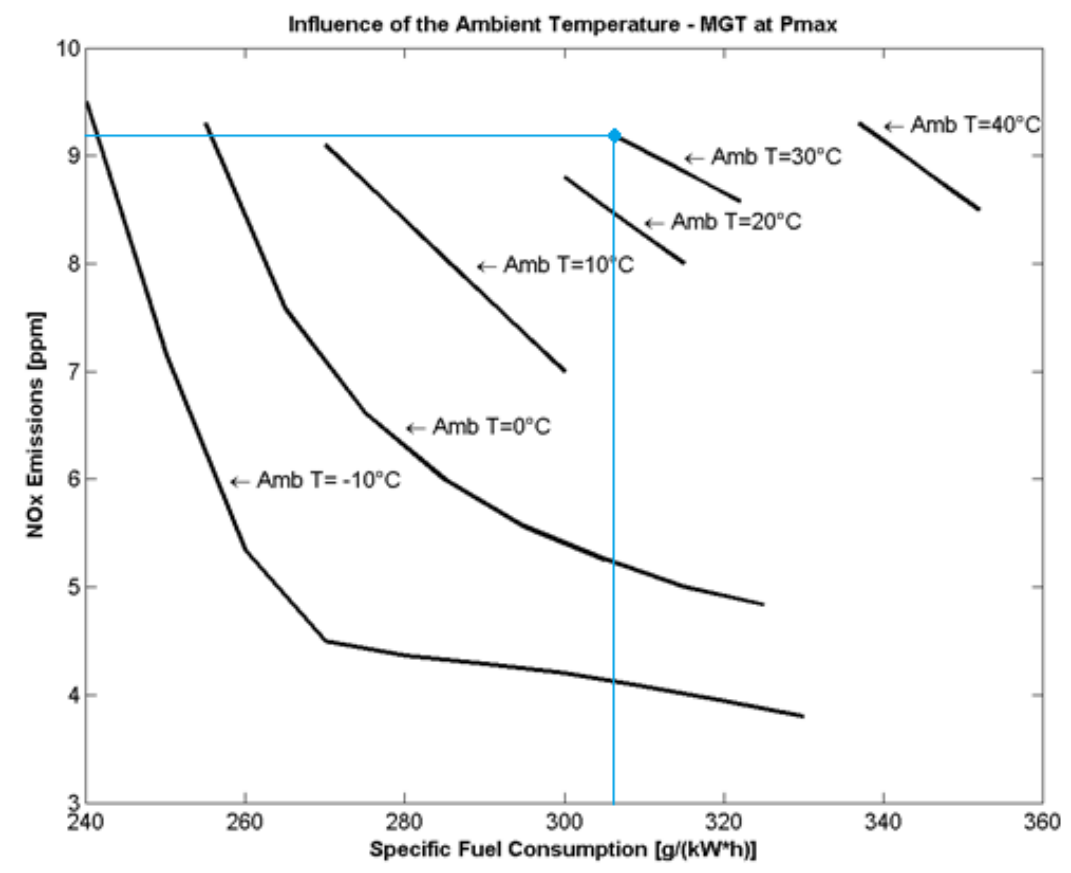

Fig. 9. Influence of ambient temperature and MGT operating point chosen 


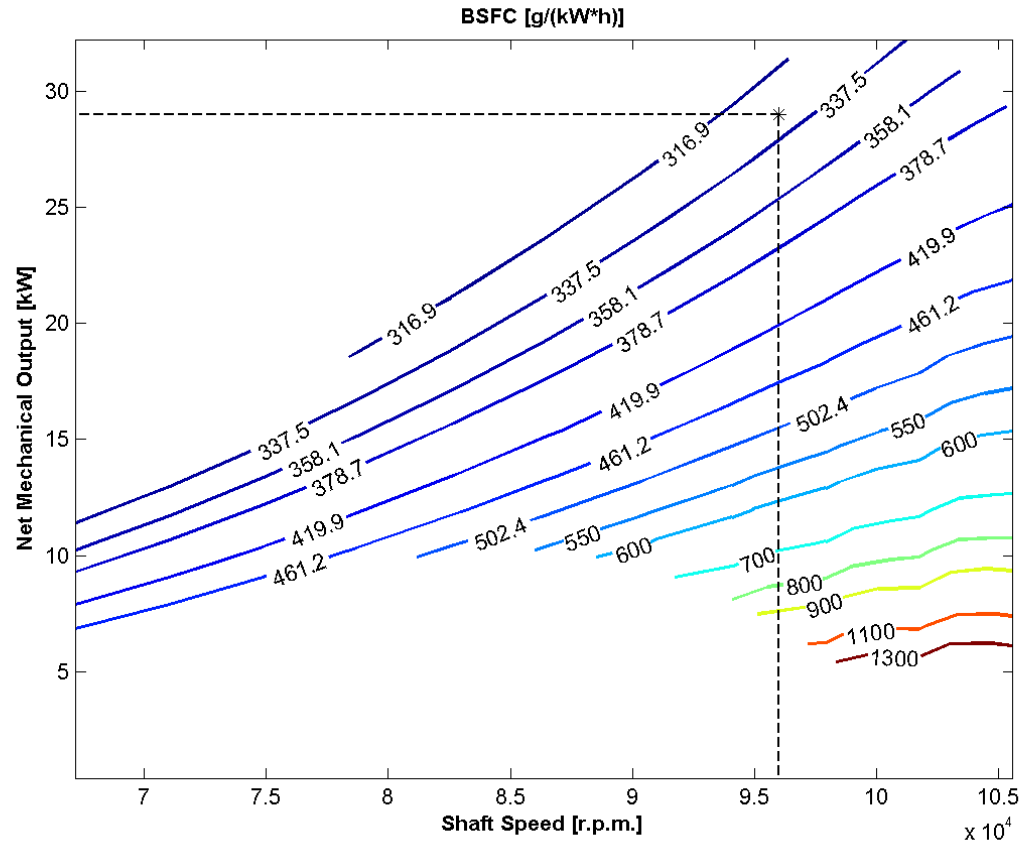

Fig. 10. MGT C30 BSFC Map-Diesel

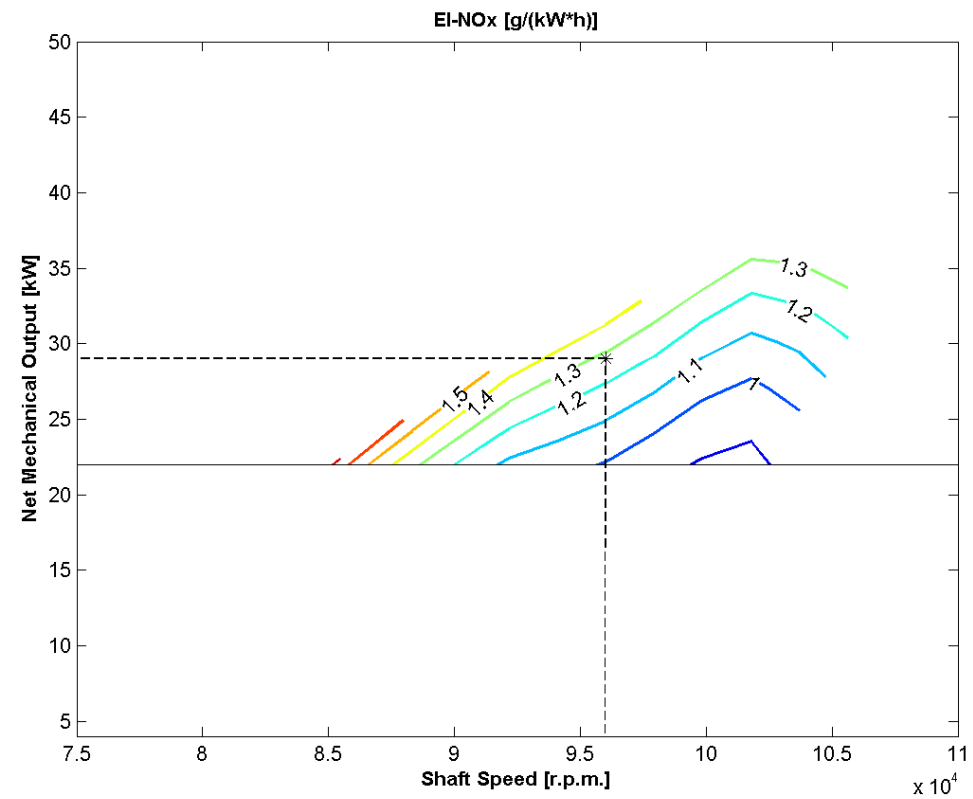

Fig. 11. MGT C30 NOx Emission Index Map-Diesel 


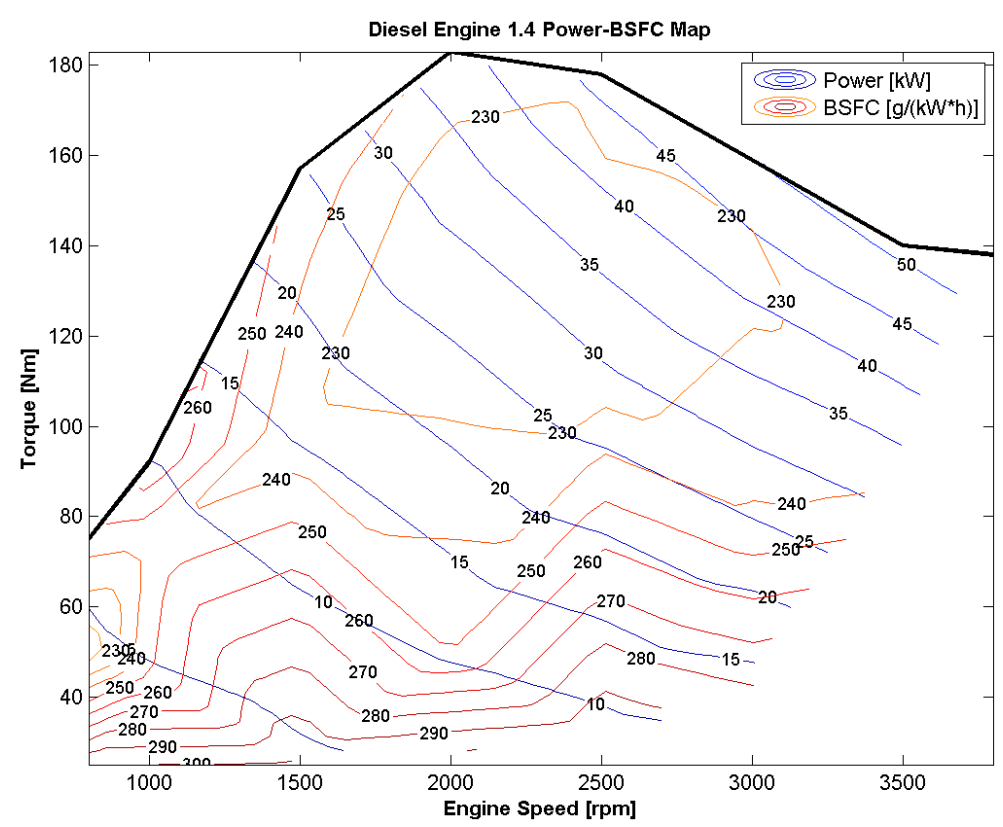

Fig 12. Diesel engine BSFC map

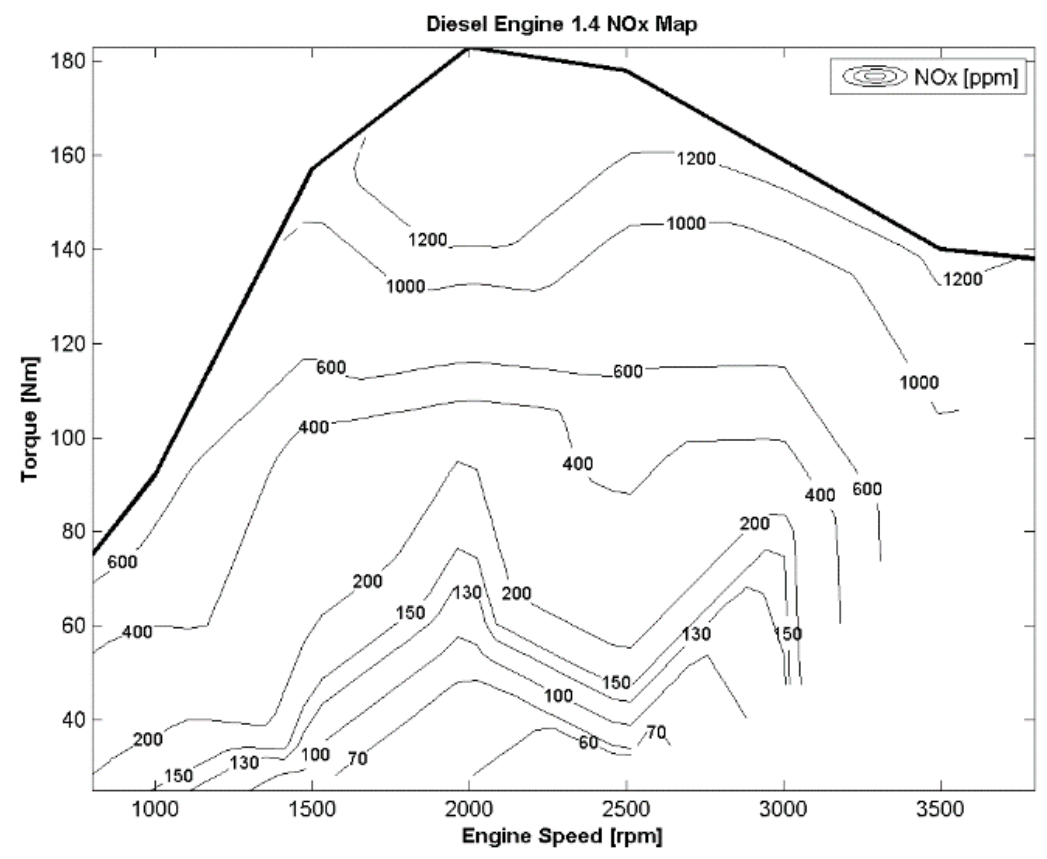

Fig 13. Diesel engine NOx map 


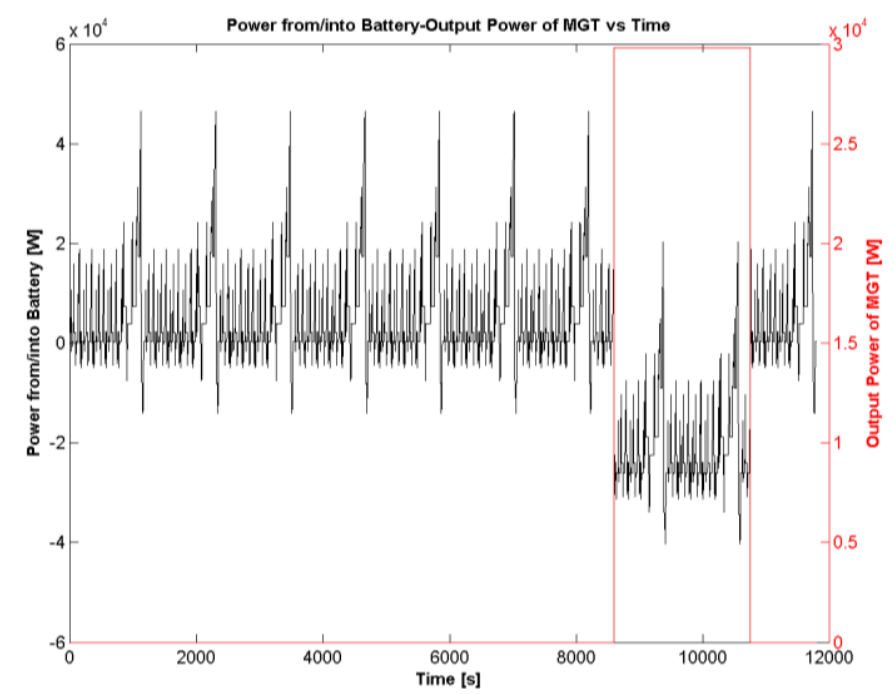

Fig. 14: Power from/into Battery-Output Power of MGT vs. Time

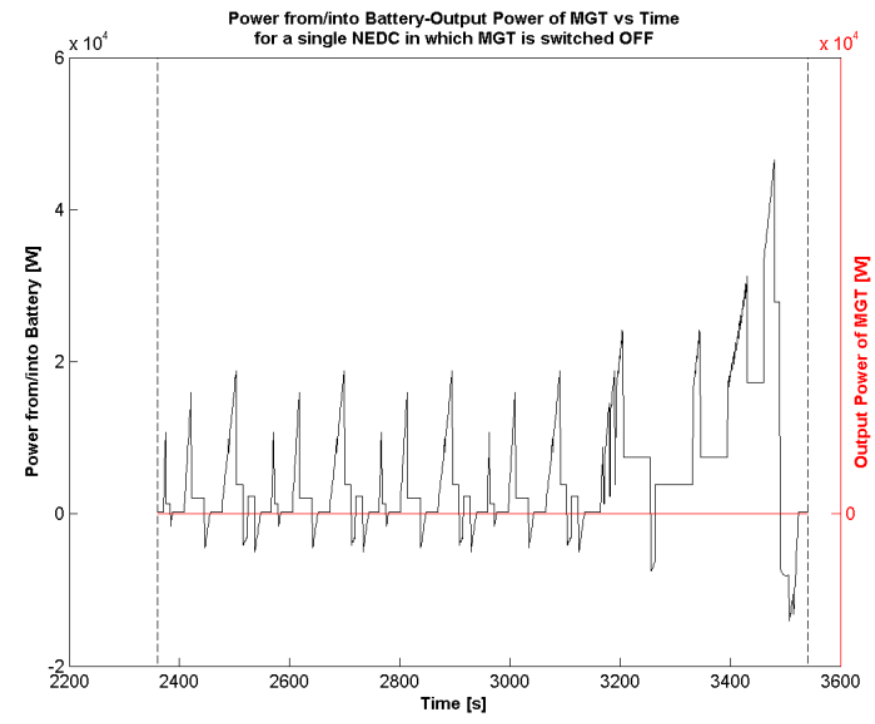

Fig. 15: Power during a single NEDC in which the MGT is switched-off 


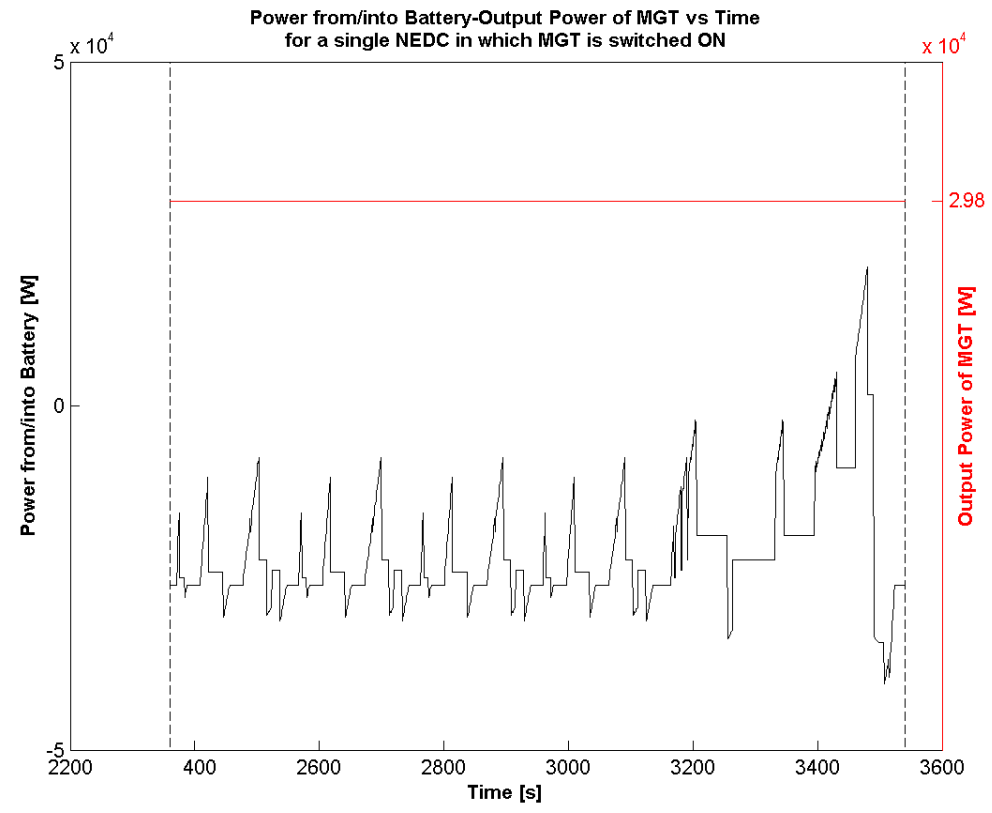

Fig. 16: Power during a single NEDC in which the MGT is switched-on

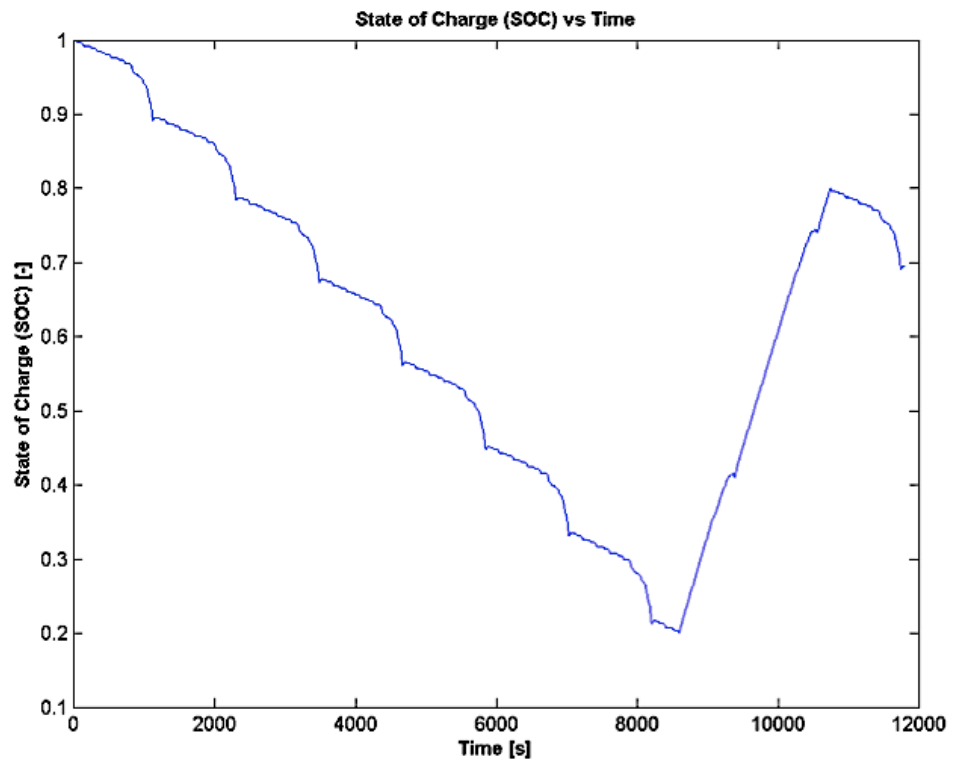

Fig. 17: State of Charge (SOC) vs. Time 


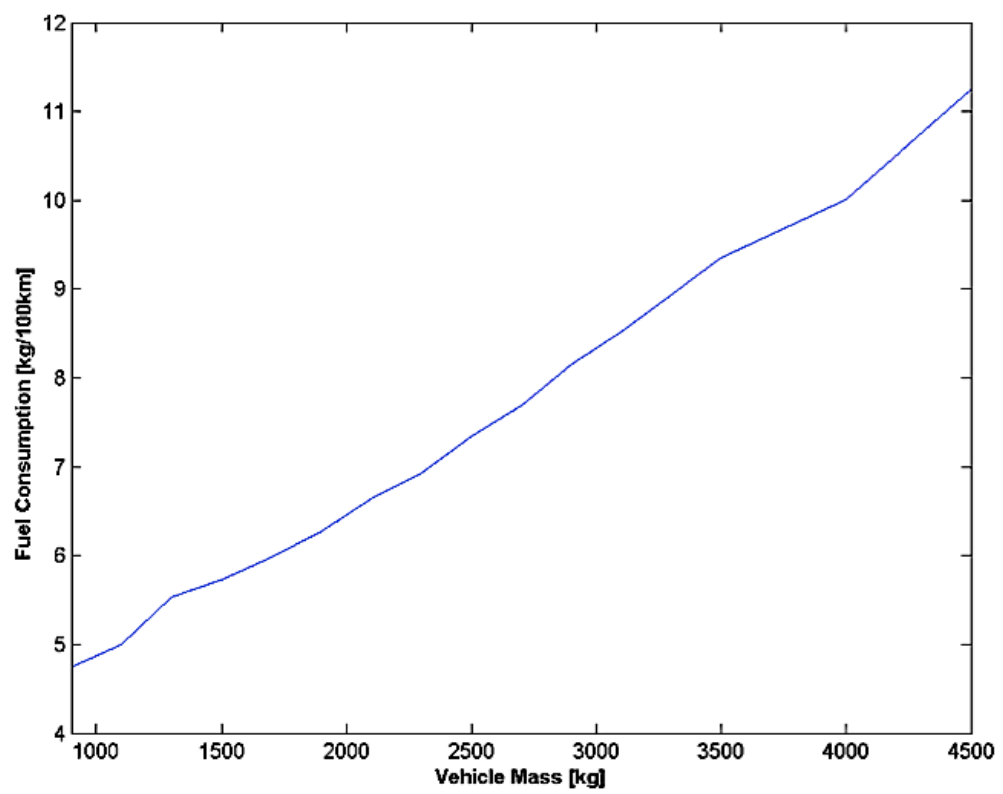

Fig. 18: Sensitivity analysis for the vehicle mass

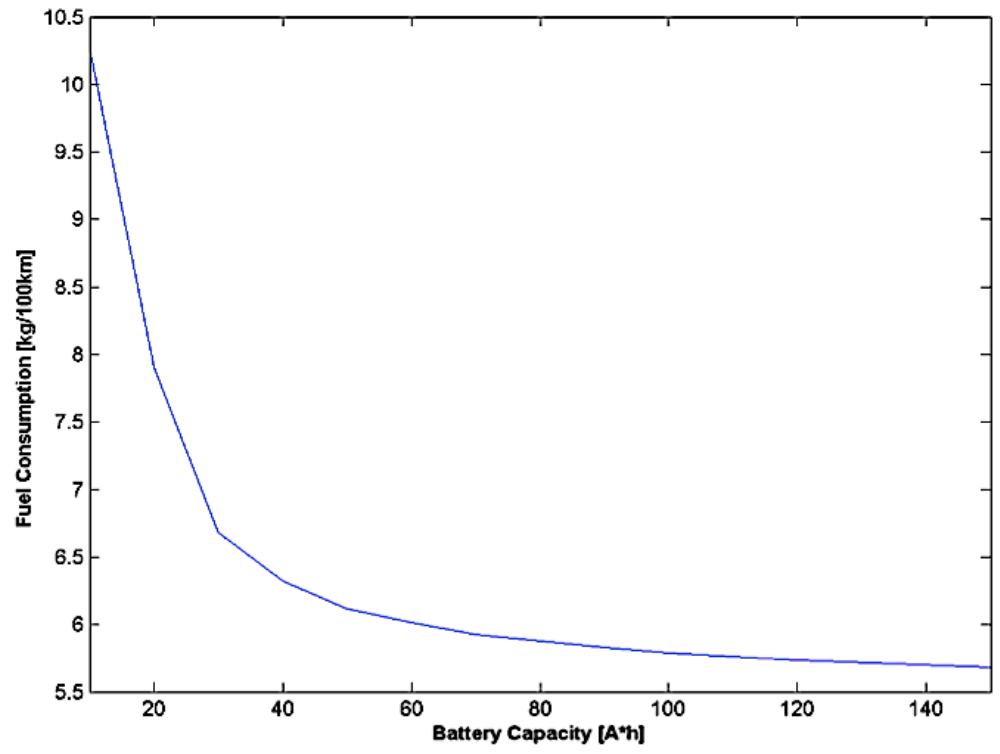

Fig. 19: Sensitivity analysis for the battery capacity (Matlab) 